\title{
Epidemiological Study of Children with Development Coordination Disorders (DCD)
}

\author{
Faten Abd El-Latif*, Hala Elgrawany*, Ibrahim El-Sawy**
}

\begin{abstract}
The objectives of the study is to determine the epidemiology of dyspraxia among preschool children in Alexandria. Method of the study: a case control study was designed. The sample of the study was 33 children (26 $\delta$ and 7 o) with dyspraxia and 33 normal children as a control. Both groups were subjected to the followings a) screening phase, b) developmental assessment and, c) clinical assessment. The results: Males are significantly affected more than females $(p=0.037)$. Prematurity $(p=0.012)$, allergic disease $(p=0.004)$, and positive family history $(p=0.000)$ are significant factors for dyspraxia. Dyspraxic children have significantly behavior problems $(p=0.008)$, speech disturbance $(p=0.000)$, and lack of imaginative play $(p=000)$. Conclusion dyspraxia is more common in males than females. Behaviour problems, speech disturbance and lack of imaginative play are more common in dysproaxic.
\end{abstract}

Key words: Dyspraxic; Developmental Coordination Disorders; Diagnostic and Statistical Manual of Diseases; International Classification of Diseases

\section{INTRODUCTION}

Developmental coordination disorder (DCD) is the term used to describe difficulties in the development of movement skills. It becomes apparent in early childhood as a difficulty in learning or carrying out skills that require motor coordination. This condition affects a child's performance of every day tasks in the home, play, and school environments. Up till now the cause of DCD is unknown, However, it is known that the difficulty arises in the processing of the information between the brain and the body, which affects the child's ability to move effectively. ${ }^{(1)}$

Dyspraxia is a neurological disorder of motor coordination usually apparent in childhood that manifests as difficulty in thinking out, planning out, and executing planned movements or tasks. ${ }^{(2)}$

Over the years dyspraxia and DCD have been used interchangeably along with

\footnotetext{
${ }^{*}$ Child Health, Kindergarten Faculty, University of Alexandria

${ }^{* *}$ Sports Psychology, Kindergarten Faculty, University of Alexandria
} 
other names such as "clumsy child syndrome. Currently the term DCD is the most acceptable term to describe these difficulties $^{(1)}$ whilst "dyspraxia" is a specific difficulty in motor planning and is a subtype of DCD. (1)

Dyspraxia may affect any or all areas of development. Physical, intellectual, emotional, social, language, and sensory and may impair the normal process of learning thus is a learning difficulty. It is not a unitary disorder and so affects each person in different ways at different ages and stages of development and to different degrees. ${ }^{(3)}$ It is inconsistent in that it may affect the child one day but not the next. It is a hidden handicap as, under normal circumstances, children with dyspraxia may appear no different from their peers, until new skills are tried or known ones taken out of context when difficulties may become apparent. Dyspraxia people can be of average or above average intelligence but are often behaviourally immature.(4) $^{(4)}$

Evidence suggests that children do not "grow out" of DCD and difficulties may extend into adolescence and sometimes into adult life. Consequently, early diagnosis and intervention is important for both child and family! With while early intervention is beneficial while the brain is changing dramatically during the first years of life and new connections and abilities are required. ${ }^{(5)}$ There is no cure for dyspraxia but the earlier a child is treated then the greater the chance of improvement. The dyspraxia foundation believes that promoting awareness will help people dyspraxic as dyspraxia to be understood, which will in turn build by their self-esteem. ${ }^{(6)}$

Early intervention during the preschool age offers a good opportunity for school failure prevention as the most significant educational effects of the condition involve fine skills such as those used in writing or drawing, or planning and self organization 
weakness may also be observed in the mechanisms of speech production such that articulation is impaired and expressive language is inhibited. There may be secondary effects in terms of poor self image and limited social acceptance by peers.

\section{PURPOSE OF THE WORK}

The purpose of the present work is to study the epidemiology of developmental dsypraxia among preschool children in Alexandria.

\section{MATERIAL AND METHODS}

A control study was carried out to determine the epidemiology of DCD among preschool children in Alexandria the initial studies sample was 473 children as 265 males and 208 females in the age range between 4-6 years attending kindergarten in Alexandria of middle socioeconomic level.

The evaluation of motor functions followed a 3 types procedure:

\section{Step 1: Screening phase:}

Using parent complete questionnaire to detect children with difficulty in motor development, based on parental reports of quantity of motor performance.

\section{Step 2: Developmental assessment:}

Children who are screened positive were assessed with a more detailed, developmental evaluation to as certain the accuracy of the screening assessment and to confirm the deficit areas and exclude other CNS diseases.

\section{Step 3: Clinical assessment:}

The following assessment was done for positively screened children:

- Test for sustaining positions against gravity.

- Test for motor screening.

- Nose-finger test.

- Motor skills screening.

- Crossing test.

- Fine motor skills evaluation (colouring drawing, building blocks, finger grip scissor activities.

Accordingly 33 children were diagnosed as having DCD (26 males and 7 females). The study design constituted: 
Group I: $\quad 33$ children diagnosed as having DCD according to the Diagnostic and Statistical Manual of Diseases (DSM) IV criteria for diagnosis. ${ }^{(7)}$

Group II: 33 normal children from the initial sample as a control group.

Both groups were subjected to the following.

- Detailed developmental history (parental questionnaire).

- Behavior assessment using behaviour assessment chicklist. ${ }^{(8)}$

- Speech disturbances using language test. ${ }^{(9)}$

- Teacher observation checklist to assess:

* Social skills, social interaction, peer relationships.

* Class activities.

* Imagination skills (by using open ended stories and role play.

\section{RESULTS}

Table 1 shows the main demographic features of the sample.
The incidence of dyspraxia children was $6.9 \%$ of all the sample. The ratio between males to females was 3.7. Table (1) demonstrates children graphic features of both groups. As regard age $(p=0.805)$ and $\operatorname{sex}(p=0.037)$.

Table 2 shows the main risk factors of dyspraxia in children

Table (2) shows the main predisposing factors of dyspraxia prematurity has a significant effect $(p=0.012)$. Also allergic disorder has a significant and rule $(p=$ 0.004) family.

Table (3): shows the main problems of dyspraxia children

Table (3) shows the main problems many dyspraxic children. These include behaviour disturbance $(p=0.008)$. Speech problems $(p=0.000)$, feeding problems ( $p$ $=0.017)$ and lack of imaginative play $(p=$ $0.000)$

Table (4) shows comparison between the two groups as regard final motive development 
Table

(4) shows

the

the two groups as regard social relative

comparison between the 2 groups as in the class

regard fine motor development $(p=<0.001)$. Table (5) shows comparison between 2

Table (5): shows comparison between groups as regard social relation in the class.

Table 1: The main demographic features of the sample

\begin{tabular}{|c|c|c|c|c|}
\hline \multirow[b]{2}{*}{ Character } & \multicolumn{2}{|c|}{ Cases $n=33$} & \multicolumn{2}{|c|}{ Control $n=33$} \\
\hline & No & $\%$ & No & $\%$ \\
\hline Age & & & & \\
\hline $4-5$ & 18 & & 17 & \\
\hline $5-6$ & 15 & & 16 & \\
\hline$\chi^{2}(p)$ & \multicolumn{4}{|c|}{$0.06(0.805)$} \\
\hline $\begin{array}{l}\text { Sex } \\
\text { Males } \\
\text { Females }\end{array}$ & $\begin{array}{c}26 \\
7\end{array}$ & & $\begin{array}{l}18 \\
15\end{array}$ & \\
\hline$\chi^{2}(p)$ & \multicolumn{4}{|c|}{$4.36(0.037)$} \\
\hline
\end{tabular}

Table 2: The main risk factors of dyspraxia in children

\begin{tabular}{|c|c|c|c|c|}
\hline Factor $\quad$ Group & \multicolumn{2}{|c|}{ Cases $n=33$} & \multicolumn{2}{|c|}{ Control $n=33$} \\
\hline Problems during pregnancy & No. & $\%$ & No. & $\%$ \\
\hline $\begin{array}{l}\text { Present } \\
\text { Absent }\end{array}$ & $\begin{array}{l}12 \\
21\end{array}$ & & $\begin{array}{c}8 \\
25 \\
\end{array}$ & \\
\hline$\chi^{2}(\mathrm{p})$ & \multicolumn{4}{|c|}{$1.15(0.284)$} \\
\hline Duration of pregnancy & & & & \\
\hline $\begin{array}{l}\text { Normal for data } \\
\text { premature }\end{array}$ & $\begin{array}{c}25 \\
8\end{array}$ & & $\begin{array}{c}32 \\
1\end{array}$ & \\
\hline$\chi^{2}(\mathrm{p})$ & \multicolumn{4}{|c|}{$6.30(0.012)$} \\
\hline History of allergic disorder & & & & \\
\hline $\begin{array}{l}+\mathrm{ve} \\
-\mathrm{ve}\end{array}$ & $\begin{array}{l}16 \\
17\end{array}$ & & $\begin{array}{c}5 \\
28\end{array}$ & \\
\hline$\chi^{2}(\mathrm{p})$ & \multicolumn{4}{|c|}{$8.45(0.004)$} \\
\hline Family history & & & & \\
\hline $\begin{array}{l}+v e \\
-v e\end{array}$ & $\begin{array}{l}19 \\
14\end{array}$ & & $\begin{array}{c}3 \\
30\end{array}$ & \\
\hline$\chi^{2}(p)$ & \multicolumn{4}{|c|}{$17.45(0.000)$} \\
\hline
\end{tabular}


Table 3: $\quad$ The main problems of dyspraxia children

\begin{tabular}{|c|c|c|c|c|}
\hline Group & \multicolumn{2}{|c|}{ Cases $n=33$} & \multicolumn{2}{|c|}{ Control $n=33$} \\
\hline Motor development & No. & $\%$ & No. & $\%$ \\
\hline Normal & 15 & & 23 & \\
\hline Delayed & 18 & & 10 & \\
\hline$\chi^{2}(p)$ & \multicolumn{4}{|c|}{$3.97(046)$} \\
\hline \multicolumn{5}{|l|}{ Behaviour disturbance } \\
\hline Present & 22 & & 10 & \\
\hline Absent & 11 & & 23 & \\
\hline$\chi^{2}(p)$ & \multicolumn{4}{|c|}{$7.04(0.0008)$} \\
\hline \multicolumn{5}{|l|}{ Speech distribution } \\
\hline Present & 29 & & 9 & \\
\hline Absent & 4 & & 24 & \\
\hline$\chi^{2}(p)$ & \multicolumn{4}{|c|}{$24.81(0.000)$} \\
\hline \multicolumn{5}{|l|}{ Imaginative play } \\
\hline Present & 6 & & 30 & \\
\hline Absent & 27 & & 3 & \\
\hline$\chi^{2}(p)$ & \multicolumn{4}{|c|}{$35.20(0.000)$} \\
\hline \multicolumn{5}{|l|}{ Feeding problems } \\
\hline Present & 15 & & 6 & \\
\hline Absent & 18 & & 27 & \\
\hline$\chi^{2}(p)$ & \multicolumn{4}{|c|}{$5.66(0.017)$} \\
\hline
\end{tabular}


Table 4: Comparison between two groups as regard final motive development

\begin{tabular}{|c|c|c|c|c|c|c|c|c|c|}
\hline & \multicolumn{4}{|c|}{ Group A (n=33) } & \multicolumn{4}{|c|}{ Group B $(n=33)$} & \multirow{3}{*}{$\chi^{2}(p)$} \\
\hline & \multicolumn{2}{|c|}{ Yes } & \multicolumn{2}{|c|}{ No } & \multicolumn{2}{|c|}{ Yes } & \multicolumn{2}{|c|}{ No } & \\
\hline & No. & $\%$ & No. & $\%$ & No. & $\%$ & No. & $\%$ & \\
\hline Colour within line & 4 & 12.1 & 29 & 87.9 & 23 & 69.7 & 10 & 30.3 & FEp $<0.001^{*}$ \\
\hline $\begin{array}{l}\text { Play with sand } \\
\text { effectively }\end{array}$ & 17 & 51.5 & 16 & 48.5 & 30 & 90.9 & 3 & 9.1 & $\mathrm{FEp}=0.001^{*}$ \\
\hline Follow dots & 10 & 30.3 & 23 & 69.7 & 31 & 93.9 & 2 & 6.1 & FEp $<0.001^{*}$ \\
\hline Print letters & 9 & 27.3 & 24 & 72.7 & 30 & 90.9 & 3 & 9.1 & FEp $<0.001^{*}$ \\
\hline $\begin{array}{l}\text { Make shapes with } \\
\text { clay }\end{array}$ & 15 & 45.5 & 18 & 54.5 & 29 & 87.9 & 4 & 12.1 & $\mathrm{FEp}=0.001^{*}$ \\
\hline Loss medline & 7 & 21.2 & 26 & 78.8 & 23 & 69.7 & 10 & 30.3 & $\begin{array}{c}\chi^{2}=15.644^{*} \\
p<0.001\end{array}$ \\
\hline
\end{tabular}

FEp : $p$ value for Fisher Exact test

$\chi^{2}:$ Chi-square test

${ }^{*}$ : Statistically significant at $p<0.05$

Table 5: Comparison between two groups as regard social relative in the class

\begin{tabular}{|c|c|c|c|c|c|c|c|c|c|}
\hline & \multicolumn{4}{|c|}{ Group A $(n=33)$} & \multicolumn{4}{|c|}{ Group B $(n=33)$} & \multirow{3}{*}{$\begin{array}{c}\text { Test of } \\
\text { sig. }\end{array}$} \\
\hline & \multicolumn{2}{|c|}{ Yes } & \multicolumn{2}{|c|}{ No } & \multicolumn{2}{|c|}{ Yes } & \multicolumn{2}{|c|}{ No } & \\
\hline & No. & $\%$ & No. & $\%$ & No. & $\%$ & No. & $\%$ & \\
\hline $\begin{array}{l}\text { Good friendship } \\
\text { with ?????? }\end{array}$ & 10 & 30.3 & 23 & 69.7 & 18 & 54.5 & 15 & 45.5 & $\begin{aligned} \chi^{2} & =3.970^{*} \\
p & =0.046\end{aligned}$ \\
\hline Play in groups & 8 & 24.2 & 25 & 75.8 & 20 & 60.6 & 13 & 39.4 & $\begin{aligned} \chi^{2} & =8.932^{* *} \\
p & =0.003\end{aligned}$ \\
\hline $\begin{array}{l}\text { Show some } \\
\text { responsibilities }\end{array}$ & 12 & 36.4 & 21 & 63.6 & 18 & 54.5 & 15 & 45.5 & $\begin{array}{l}\chi^{2}=2.200 \\
p=0.138\end{array}$ \\
\hline $\begin{array}{l}\text { Good relation in } \\
\text { meal time }\end{array}$ & 11 & 33.3 & 22 & 66.7 & 25 & 75.8 & 8 & 24.2 & $\begin{array}{c}\chi^{2}=11.978^{* *} \\
p=0.001\end{array}$ \\
\hline
\end{tabular}

$\chi^{2}:$ Chi-square test

* : Statistically significant at $p<0.05$ 


\section{DISCUSSION}

Developmental coordination disorder is a chronic and usually permanent condition found in children, is characterized by motor impairment that interferes with the child's activities of daily living and academic achievement. A decade ago, researchers estimated that DCD occurred in 10\%-19\% of school-aged children, with a more precise definition of $D C D$, the current prevalence is estimated to be between $5 \%$ and $8 \%$ of all school-aged children.(10) In the present study, the prevalence of dyspraxia among the studied samples was $6.9 \%$.

In whole populations sex differences are not significant, though twice as many boys have difficulties as girls. Clinic-based studies show a ratio of $4: 1$ suggesting that boys react to their difficulties in a more conspicuous way, or that there are higher expectations in performance of boys than girls. ${ }^{(4)}$ Chambers and Sugden reported a

2:1 ratio, but claimed that the difference may reflect higher referred rates for boys. ${ }^{(11)}$ Portwood $2001^{(4)}$, explains this difference by the research evidences that female brains use both hemispheres to process language (predominantly a left hemispheric function) and spatial tasks (predominantly a right hemispheric function). Where there is evidence of immaturity in the left hemisphere the characteristic presenting symptoms are those of dyslexia where the immaturity is basal in the right hemisphere the symptoms are those of dyspraxia. Statistics say that the ratio of boys to girls with both conditions is somewhere in the region of 4 or 5 to 1 . the incidence of girls identified as having either difficulty will be reduced because of the residual functioning in the opposing hemisphere. If there are difficulties with the left hemisphere in boys they do not have any additional backup 
systems and so the problem persists. In females, where both sides of the brain have operative function, the difficulties will be reduced in many cases to a level where they are not significant. ${ }^{(12)}$

Regarding the risk factors of dyspraxia in the present study, statistical analysis showed significant difference as regards the duration of pregnancy, family history for allergic disorder, and family history of similar condition. Gubbay (1985) ${ }^{(13)}$ suggested that in perhaps $50 \%$ of diagnosed cases of dyspraxia significant factors are evident during pregnancy, labor, and birth. Portwood, 2001(4), mentioned that $82 \%$ of the studied sample to include: Prolonged labor, Prematurity, and Postmaturity.

As regards the predisposing factors, Portwood, 2001(4), considers dyspraxia, dyslexia, attention deficit, hyperactivity disorder, and autism under the category of neurodevelopmental disorders, he reported that all these disorders have been associated with fatty acid abnormalities ranging from genetic abnormalities in the enzymes involved in phospholipid metabolism to symptoms reportedly improved following dietary supplementation with long chain fatty acids.

Richardson et al., 2000(14), states that the predisposition to dyspraxia and related conditions may involve mild constitutional inefficiencies of fatty acid metabolism that increases usual dietary requirements for Highly Unsaturated Fatty Acids (HUFA.) These could include a poor Essential fatty acids - Highly Unsaturated Fatty Acids (EFA-HUFA) conversion or difficulties in incorporating HUFA into brain cell membrane and/or unusually high rate of HUFA breakdown and loss. Richardson et al.,(14) also maintains that many features associated with dyspraxia are consistent with HUFA deficiencies or imbalances. These include the core difficulties with motor coordination, attention, and sensory processing, as well as the excess of males 
affected, proneness to allergic or developing normally smooth, targeted, and autoimmune conditions, irregularities of accurate movements, both gross and fine mood. requiring the harmonious functioning of

One of the main risk factors is sensory input, central processing this prematurity, this is because the more information in the brain, and coordination premature the baby, the more the migration with the high executive cerebral functions and connections of neurons may be (e.g., volition, motivation, and motor distributed leading to difficulties with attention span, self control, self inhibition and motor coordination problems. ${ }^{(15)}$ Genetic influences may also contribute to motor coordination as revealed by Landgren et al., (1998)(16) study which noted familial clumsiness in a study on 1134 children in Sweden. This is in accordance with our study that reveals significant increase in children with positive family history of dyspraxia. While dyspraxia describes physical coordination difficulties, the associated problems are not limited to this sphere because motor coordination is the product of a complex set of cognitive and physical processes that are often taken for granted in children who are planning of an activity). Also required is the performance of a certain motor pattern. These elements must work in a coordinated and rapid way to enable complex movements to involving different parts of the body. Motor planning consists of the ability of children to imagine a mental strategy to carry out a movement or an action. In this study, children found to lack imagination this is in accordance with Wilson's study $(2000)^{(17)}$ which revealed that children with DCD have an impairment in the ability to generate internal representation of optional movements. Also Wilson (2000)(17) maintains that children with DCD have difficulties in generating an accurate representation of an intended 
action which is shown by deficits in motor imagery.

As regards the motor delay and the behavior disturbances significantly seen in these studied samples, they might be explained on the basis of Jean Ayer ${ }^{(18,19)}$ sensory integration theory, sensory integration refers to functioning of the brain the central concept of the theory is that children may struggle to integrate sensory input (e.g., visual, auditory, tactile and proprioceptive cues, and develop aversions) (i.e., to being touched, to being exposed to new sounds). Also children may become overstimulated in any of these sensory channels, and their behavior and motor performance deteriorate in circumstances of overstimulation. She concluded that children with motor difficulties often have problems in the integration of sensory input, which make them vulnerable to problems resulting from sensory stimulation. ${ }^{(18,19)}$
Difficulties with motor planning are often at the least of these children frustrations. As children grow, they move away from simply experiencing the world and are instead called upon to master it. Toys, tolls and self-care activities become more complex, requiring more intricate and sequenced motor planning behavior. Motor planning problems make it difficult for these children to master the use of objects, which leads to an increasing sense of frustration. ${ }^{(13)}$ Recent studies reveal the importance of the limb praxis system which is a neural system important in higher-level motor control related to the accurate selection and programming of skilled movements. Clinical research has shown that the praxis system is comprised of a complex network of brain regions in the left cerebral hemispheric, including areas in the posterior parietal lobe and in dorsal and lateral frontal cortex. An intact praxis system is necessary for the accurate production of skilled hand and arm 
gestures on demand, also known as normal "limb praxis". The system controls both representational and nonrepresentational movement, i.e., movements that convey symbolic meaning (e.g., wave good bye) and those that do not (e.g., place fist on head). Chigman and Hampson 2007(12) suggest a female advantage in gesture production emerge as early as 3 years of age, this fact raises the possibility of a hormonally mediated mechanisms. This has led to the hypothesis that more focal representation might afford females greater precision over the control of skilled movements whether manual or vocal. According to Kimura's view $(1993)^{(20)}$, a sex differences in the praxis system would be expected to affect not only prexis but also oral motor control, because both musculature are served by overlapping components of the praxis system.

In a disorder as complex as dyspaxia it may be disguided to search for one primary deficit capable of accounting for all the observed manifestation of the disorder and whether their manifestations are correlated or secondary consequences of a primary or multiple deficit. ${ }^{(20,21)}$

Because the development of pretense, receptive and expressive language, and mental representation all begin at approximately the same age (usually between age 1 and 2) researches have hypothesized strong conceptual relationships between these processes. Recent research suggests that Broca's area (Beordmann area 44) a brain region critical for language may have evolved from neurons active during observation and execution of manual movement. ${ }^{(22)}$

Because while it is true that many are diagnosed people have some form of dyspraxia which is most likely neurobiological in origin. It is unclear whether dyspraxia is merely one of the 
many factors that may induce asperger style behavior or is comorbid with the condition.

Recently, a new category is described as non-verbal learning disabilities (NonVerbal Learning Disabilities (NVLD)) affect organization, motor skill visual spatial perception, non-verbal communication, and often mathematics non verbal learning disabilities are very closely related to asperger syndrome hyperbaxia and Dyspraxia. Rourka (1995) has grouped these into three major areas, neuropsychological deficits, academic deficits, and social emotional/adaptational deficits. Neuropsychological deficits include difficulties with tactile and visual attention, non-verbal memory, reasoning, executive functions and specific aspects of speech and language deficits in math calculations, mathematical reasoning, reading comprehension specific aspects of written language and execution of manual movements. Imaging studies showing increased Broca's activity during execution, imagination imitation and observation of hand movement support this hypothesis. Heisu et al., suggest that Broca's area has an essential role in imitation of finger movement. This excludes the possibility that this region of the human is exclusively dedicated to language processing and rather suggests an evolutionary continuity between action recognition, imitation and language, and shared neural mechanisms for all these forms of communications between individuals. ${ }^{(22)}$

Although, in the DSM IV \& ICD10 classification dyspraxia or DCD is well differentiated from other developmental disorders that many people with autistic spectrum disorders have the same kinds of difficulties and may be diagnosed with dyspraxia handwriting are primary academic concerns. Social deficits include problems with social perception and social interaction. Children with this disorder are also seen as having substantially increased 
risk for internalized forms of psychopathology, primarily anxiety, and depression (Rourke 1989).(24) The NVLD syndrome has been described as a diagnostic entity only recently. This explains the fact that it has no entry DSMN or ICD10 classification. Rourke suggests a dynamic model speculating that primary neuropsychological deficits lead to secondary deficits in modality specific aspects of attention and more generally in the extent to which children activity explore their environment. ${ }^{(23)}$ These primary neuropsychological deficits include tactile perception, visual perception and motor coordination. In turn, these secondary deficits lead to tertiary deficits, particularly in non-school memory, abstract reasoning, executive functions, and specific aspects of speech and language specific measurable impairments in academic performance, social functioning and emotional well being are direct byproducts of this constellation of primary, secondary or tertiary neuropsychological deficits the accuracy of the diagnosis being directly proportional to the number and magnitude of symptoms present that are consistent with the diagnosis.

The Learning Disabilities Association of America stresses the importance of early intervention owing to the fact that the early years of life are a period of phenomenal growth and learning. Early intervention with the toddler at risk for learning disability, as suggested by developmental signs including those for developmental coordination disorder, will improve the child's chances of future school success, reduce the need for special education services in later years, and minimize the loss of self esteem brought on by school failure. Motor skills, both gross and fine, and social interaction are fundamental for successful school performance. The present study reveals significant impairment of these skills in children with NVLD. It is, therefore, essential that early 
screening for positive signs of dyspraxia

early intervention strategies be seriously

considered in the management of children

identified as having this condition.

\section{REFERENCES}

1. Dyspraxia/DCD Association cork in co-operation with the DCD unit. St. Finbarrs Hospital Cork: Developmental Coordination Disorder Practical tips for parents. p:2.

2. Dyspraxia: Definition and much more from Ans was Com. Health: New Logical disorder. Availablr from: http://www.answers.com/topic/dysprox iacat =health.

3. Developmental Dyspraxia: What is Dyspraxia? Available from: http://www.dysproxia.org.nz/what is.htm.

4. Portwood. M Understanding Developmental Dyspraxia. 2001.134.

5. Dyspraxia Foundation. Recognising developmental coordination disorders. Dyspraxia Foundation Publication; What is developmental dyspraxia?

6. McCormick L, Schiefelbusch RL. Supporting children with communication difficulties in inclusive settings. Boston, UA: Allyn and Bacon; 1997.

7. Connor M. Dyspraxia: general information and guidelines. Available from: http://www.mugsy.org/connor25.htm. 1996.

8. Jellinuk $M$, Murphy $M$, Comer $D$, Kelleher K. Use of the pediatric symptom checklist to screen for psychosocial problems in pediatric primary care. Arch Ped. Adol Med. 1999; 153: 254: 60.

9. Gardner MF. Expressive one-word picture vocabulary test: manual.
Novato, CA: Academic Therapy Publications; 1990

10. Duran M. Motor skills disorders. Medicine. 2005; (3).

11. Chambers HC, Sugden DA. A twostep procedure for the identification of children with developmental coordination disorder in Singapore. Dev Med Child Neurol. 1996; 38(12): 1099105.

12. Chigman R, Hampson E. A female advantage in the initiation of gestures by preschool children. Development Neurology. 2007; 31(2): 137-58.

13. Gubbay SS. Clumsiness. In: Vinken $P$, Bruyn G, Dlawans H. (eds). Handbook of clinical neurology. New York: Elsevier; 1985.

14. Richardson AJ, Clavin CM, Clisby C, Schoenheimer DR, Montogomery P, Hall JA, et al. Fatty acids deficiency signs predict the society of reading and related difficulties in dyslexic children. Prostaglandins, Leukotriens and Essential Fatty Acids. 2000; 63(1/2): 69-74.

15. Ward PE. Potential diagnostic aids for abnormal fatty acid metabolism in a range of neurodevelopmental disorders. Prostaglandins, Leukotrienes and Essential Fatty Acids. 2000; 63(1/2): 65-8.

16. Landgren $M$, Kjellman B, Gillberg $C$. Attention deficit disorder with developmental coordination. Arch Dis Child. 1998; 79(3):207-12.

17. Wilson $\mathrm{PH}$. Motor injury training ameliorates motor clumsiness in children. J Child Neurol. 2000; 17: 291-8.

18. Jeanerod M. Neural stimulation of action: a unifying mechanism for motor cognition. Neuroimage. 2001; 14: 5103-9.

19. Jeannerod $M$, Jacob $P$. Visual cognition a new look at the two-visual 
systems model. Neuropsychologic. 2005; 43: 301-12.

20. Kimura D. Sex differences in cerebral organization for speech and proxic functions. Canadian Journal of Psychology. 1993; 37: 19-35.

21. Kimura D, Hampson E. Neural and hormonal mechanisms mediating sex differences in cognition. In: Vernon PA. (ed). Biological approaches to the study of human intelligence. Norwood, NJ: Ablex Publishing Group; 1993. 375397.

22. Heiser M, Lacoboni M, Maeda F, Marcus J, Mazziotta J. The essential role of broca's area in initiation. European Journal of Neuroscience. 2003; 17: 1123-8.

23. Rourke BP. Introduction: the NLD syndrome and the while matter model. In B.P. Rourke (Ed), Syndrome of nonverbal learning disabilities: Neurodevelopmental Manifestations.

New York: Guilford Press; 1995. 1-26.

24. Rourke BP. Nonverbal learning disabilities: the syndrome and the model. New York: Guilford Press; 1989. 
